\title{
The Screen Test 1915-1930: How Stars Were Born
}

\author{
Elizabeth Ezra and Ana Salzberg
}

Key words: stardom, Louise Brooks, transnational, Hollywood, Europe, screen test Accepted for publication in Celebrity Studies, published by Taylor and Francis

Email addresses for correspondence:

Elizabeth Ezra

Professor of Cinema and Culture

The University of Stirling

e.r.ezra@stir.ac.uk

Ana Salzberg

Lecturer in Film Studies and Visual Culture

The University of Dundee

a.salzberg@dundee.ac.uk 


\title{
The Screen Test 1915-1930: How Stars Were Born
}

\author{
Abstract: \\ This article examines the emergence of the screen test as a cultural phenomenon \\ during the silent era in the US and Europe and its role in the development of the star \\ system. The lore that grew up around the screen test almost from its inception held \\ out the possibility for members of the public to cross a threshold into the rarefied \\ world of celebrity. The screen test itself is situated in the liminal space not only \\ between audience and actor, but also between fiction and non-fiction, Europe and \\ Hollywood, the silent era and the talkies, and the public and private spheres. In order \\ to trace the ways in which the screen test as such was narrativized and \\ conceptualized in its foundational stages, this article will analyse accounts from \\ Hollywood and European fan magazines of the silent era, including articles, short \\ fiction, and early cinema apocrypha. The article culminates in a discussion of the film \\ Prix de Beauté / Beauty Prize (Augusto Genina, 1930), which starred Louise Brooks, \\ herself a transnational film icon whose film career spanned the divide between \\ Hollywood and Europe. The film's final scene, in which a beauty queen is shot dead \\ by her jealous husband as she watches a screen test of herself, has been invoked by a \\ number of film scholars as an allegory of the work performed by cinema, which \\ preserves and disseminates the image of the star far beyond the actor's physical \\ presence. Speaking to historical conditions of star-making while also capturing its \\ resonance in cultural mythology, the conclusion of Prix de Beauté allows us to \\ consider the origins and functions of screen test discourse itself.
}




\section{The Screen Test 1915-1930: How Stars Were Born}

At the end of the Franco-German coproduction Prix de Beauté / Beauty Prize (Augusto Genina, 1930), Lucienne, the beauty queen and budding film star played by established film star Louise Brooks is shot dead by her jealous husband as she watches a screen test of herself. This scene has been cited by many film scholars, including Laura Mulvey and Mary Ann Doane, as an allegory of the work performed by cinema itself, which preserves the image of the star beyond the actor's physical presence (Mulvey 2006: 176; Doane 1991: 77-78, 93-94). This iconic scene bears even more symbolic weight when we consider the function of the screen test both within film history and as a cultural phenomenon. Long perceived as a gateway to stardom, the screen test represented a chance for "ordinary" members of the public, especially young women, to enter the world of celebrity. Yet the screen test not only marks the threshold to stardom: its origins are also situated in the liminal space between genres (fiction and documentary), geographical regions (the US and Europe), eras (silent and sound), and between public sphere (as a practice mythologized in fan magazines) and private sphere (an audition viewed by only a small number of film personnel, at least in the days before screen tests were circulated widely through new media).

Delving into these questions of duality, performance, and authenticity, this article will explore the origins of the screen test itself as what anthropologist Hortense Powdermaker described as a key element in "the considerable mythology concerning how stars are made" (1951: 229). It will look closely at the period between the early 
'teens to 1930 - from the development of the individual star persona to the advent of the talkies - to trace the evolution of the screen test as international cultural phenomenon, first analyzing fan magazine articles, short fiction, and early cinema apocrypha before focusing on Louise Brooks's performance in Prix de Beauté. This body of work, as we will discuss, speaks to historical conditions of star-making while also capturing its resonance in cultural mythology - and so offers a lens through which to view the origins and functions of screen test discourse itself. If, as Irene Gustafson has remarked, the screen test is "a ubiquitous albeit mostly invisible genre" (op.cit. 3; emphasis added), the following will seek to make visible the screen test's foundational role in the shaping of celebrity culture.

Stardom arises in the era of mechanical reproduction, which makes possible a simultaneous rapprochement and distancing effect, a machine-made aura to replace that lost by the decline of "live" contact with a work of art or a performer (the aura having been described by Benjamin as "a phenomenon of distance, no matter how close it may be" [1969: 222]). Stars must be other-worldly, like the celestial body for which they are named; yet at the same time, viewers must feel they have an intimate rapport with an actor, the possibility of crossing the threshold that divides their ordinary lives from the extraordinary circles in which the star moves. This thresholdcrossing potential is created by the dissemination and/or invention of supposedly "intimate" knowledge of a star's life (loves and heartaches, but also details of trips to the grocery store or the gym). But access to celebrity must be a two-way street: it is reinforced by the idea that any fan, however ordinary, could him- or herself cross over to the other side. Today, television viewers send in audition tapes to reality shows and make pilgrimages to the $X$ Factor auditions. Before the era of televised talent shows, however, fans who longed to be discovered pinned their hopes on passing a cinematic 
screen test, and fan magazines exploited this desire by publishing fictional accounts and how-to guides that chronicled the process, as well as sponsoring competitions to search for the next big star.

The screen test is a key component of the development of the star in both an individual and a cultural sense, not least because its liminal generic status coincides with what Mulvey calls the star's own "ambivalent existence both inside and outside fictional performance" (161). As Mulvey points out, the classical-era industry itself sought to control that off-screen existence, "hanging its fictions onto a star system" that - once actors had, literally and figuratively, passed the test - sculpted their overall image (162). This focus on the individual star persona originated around 1913/1914, according to Richard DeCordova:

[t]he star emerged out of a marked expansion of the type of knowledge that could be produced about the player. The picture personality was defined ... by a discourse that restricted knowledge to the professional existence of the actor. With the emergence of the star, the question of the player's existence outside his or her work in film became the primary focus of discourse. The private lives of the players were constituted as a site of knowledge and truth. (2001: 98)

In the 1920s, the fascination with stars' personal lives was fed by fan magazines, which supplemented what viewers were able to see in films with supposedly inside information about the actors" "real" lives, thus proclaiming, according to Gaylyn Studlar, "both the lack in the image in relational terms. . and its fullness of 
expression, a fullness (of the star) that the screen could not at any one time capture, that eluded the immediate field of vision" (1999: 292).

The advent of the talkies marked still another development in the star-making process, introducing as it did the need to move beyond the "immediate field of vision" as identified by Studlar and into an equally affecting aural register. Donald Craftton notes that early responses to the sound revolution suggest that,there emerged a "distinction between the silent film's emphasis on the body and the talkie's accent on the mind. Ideals of athleticism, beauty, and 'it' (sex appeal) no longer sufficed in the sound film" (Crafton 1999: 449). The eventual integration between a performer's visual and aural impact was designed to "convey a sense of illusionistic "presence"" (Crafton 1999: 459), rendering stars as flesh-and-blood creatures viewers could imagine one day actually meeting — or even being. Edgar Morin would offer more abstract commentary on the transformation from silents to sound - conceiving of a star who flitted between the celestial and the terrestrial. According to Morin, "Henceforth the stars participate in the daily life of mortals: they are no longer inaccessible: they are mediators between screen-heaven and earth" (Morin 2005 [1957]: 23-25). Certainly the mythology that grew up around the screen test in the silent era paved the way for this new kind of stardom with the link it provided between audience and actor, the ordinary and the extraordinary — and the siren call of possibility, however remote, that the former could become the latter.

\section{The Screen Test 1915 - 1930: Cautionary Tales}

In the early days of the film industry, fan magazines were fundamental in cultivating the spectator's fascination with star-making; even as articles and interviews exalted 
the triumphs of established stars, they also addressed the hopeful readers who themselves had dreams of fame. In a 1916 Motion Picture article entitled "How to Get In!" for example, the director of the Vitagraph Company, Ralph Ince, noted that while it would be helpful to submit still photographs to casting directors, "it cannot be determined from these photos whether a person will register and photograph well, as the movie camera differs greatly from the still camera. It has strong likes and dislikes" (1916: 101). According to Ince,

it would be better for the applicant to have a few feet of film taken of himself, or herself, somewhere, and send this with the application. I do not know of any companies that render this service, but I have, however, heard of a few studios that are willing to make this expensive test if impressed by the looks of an applicant. (102)

Evoking not only the anthropomorphized mystery of the movie camera and its "likes and dislikes" in this foundational era, Ince's statement also captures the incipience of the screen test as such. Not yet totally incorporated into the mechanics of star-making, the screen test of Ince's description is a luxury for studios rather than a necessity; yet various magazines' depictions of the test reveal its steady integration into both the industry and popular imagination. Advertisements for a 1915 book called Motion Picture Acting, which promised to tell readers 'What the Director's 'Photo Test' IS [and] How to prepare for this at Home"1; star-searching contests like Photoplay's 1915-1916 "Beauty and Brains" campaign; short stories and serials including Frederic Arnold Kummer's “The Test” (1917) and "Signing Up Cynthia" (1918) - all worked 
to create a grand narrative of stardom in which the screen test featured as a central player.

Again, the screen test invites explorations of its liminal status between documentary and fiction and, from a contemporary critical perspective, film history and new media. The screen test, as Avital Ronell says of the test more generally, "scans the walls of experience, measuring, probing, determining the 'what is' of the lived world. At the same time, but more fundamental still, the very structure of testing tends to overtake the certainty that it establishes" (2007: 5). Indeed, early fan magazine writers themselves chronicled the test's capacity for uncertainty. Part romanticized enigma, part technical process, the test emerged as a Janus-figure in indepth articles like "What is a Screen Test?" (1922), in which Helen Christine Bennett admitted that "[n]o two producers, directors, or actors to whom I have talked have ever agreed as to what constituted a screen test" (1922: 18), and "Could You Face the Camera?", in which Selma Robinson recorded several sobering observations for Motion Picture's readers (1926). Though hopefuls believe that "having attained at last the right to a camera test they can prove their worth to directors, cameramen and the rest of the world" (Robinson 1926: 37) the test is in fact "merely a way to find out whether one's features screen well. If they do, that is an excellent send-off" (Robinson 1926: 107). Robinson concludes, "What happens after that is up to two controlling factors - the lucky break and ability" (Robinson 1925: 107). That is, in a merging of near-mysticism and pragmatism, the notion of cinematic destiny ("the lucky break") can only be set in motion by the materiality of the screen test ("an excellent send-off") itself.

Certainly the lore of the screen test in these accounts bears with it an intrinsic double bind, cautioning young hopefuls against getting those hopes too high, while 
extolling the screen test as an instrument of providence. This ambiguity played out in articles as (ostensibly) lighthearted as "How to Make Your Own Screen Test" (1926), which informed readers that "all [they] need[ed] [was] a string and a face" to test the harmony of their proportions - but concluded with a decidedly double message: "After you have made your measurements . . you may understand why directors have such difficulty in finding screen types. Or will you? Perhaps you, too, may be one of the elect" ("How to Make Your Own Screen Test" 1926: 86). All the more evocative was a passage on the discovery of Jean Harlow, published in a Photoplay article on Howard Hughes' 1930 movie Hell's Angels (“4 Million Dollars and 4 Men's Lives” by Bogart Rogers):

One day [actor] Ben Lyon brought a girl friend to the lot, and got her a test. She was from Chicago, her name was Jean Harlow, and she was just nineteen. She clicked at once. As Harry Lang says, she was 'lusciously sexquisite and utterly inexperienced in pictures.' It was this untried girl that Hughes entrusted with the leading feminine role in his mad, wonderful adventure. (Rogers 1930: 120; emphases added)

Like many of the readers themselves, Harlow was once a hopeful, "untried girl" - but one whose own dreams of stardom were realized by passing a screen test. The vast majority, of course, were not so lucky, and this message was subtly conveyed in what Studlar calls "a superior, distanced awareness of the star-making process," resulting in “a type of so-called fetishistic 'I-know-but-nevertheless' balancing of knowledge and belief that is often considered to be impossible for women spectators" (Studlar 1999: 273, 269). 
Related fictional accounts of women's lives transformed by screen tests had to temper the potentially liberating aspect of a career in films with a moralizing caveat about the perils of trading domestic tranquillity for the silver screen. In "The Test," a 1917 short story by Arnold Kummer that appeared in Photoplay in serial form, a film director sets out to tell the story of how Betty Mason, née Joyce, came to be a movie star, but as he recounts it, it becomes clear that the story is actually more concerned with her loyalty to her husband. Betty pursues a career in the limelight without the knowledge of her disapproving male partner, a transgressive decision that nearly results in murder. (As if to underscore the importance of keeping one's husband happy, on page 16 of the same issue of Photoplay, there is an advertisement for a book called A Thousand Ways to Please a Husband, about the "Romance of Cookery — and the inspiration of housekeeping.") The screen test itself is virtually elided in "The Test," mentioned only in passing or retrospectively; yet it bears a symbolic weight that far exceeds the time devoted to it in the diegesis. It furnishes not only the story's title but also its overarching moral, which Kummer hands to us on a silver platter: "Curious thought, isn't it; that test Betty made for the screen turned out to be another sort of test altogether - a test of her love for her husband, and in a way, of his love for her" (Kummer 1917: 104). Enhancing all of these accounts, both fictional and factual (relatively speaking), is still another duality, one linked to a kind of topography of stardom. In the article cited above, for instance, Harlow made the journey from obscurity in Chicago to Hollywood and subsequent glory. In earlier features, finalists in the "Beauty and Brains" competition are invited "All Aboard for Star-Land!", where they will "view in $[$ sic $]$ projection room at Fort Lee studios the test films in which they acted” (“All Aboard for Star-Land!” 1916: 54), while still other, less fortunate young women are virtually banished from Star-Land: 
From all over the country they come, these girls, with their little hoards of savings. Two girls last summer walked all the way from Seattle [to Los Angeles] to try to find their fame in the pictures! . . A test was made, but they were photographically impossible, and the City Mothers took up a collection and sent them home. (Kingsley 1917: 68).

It is fitting, then, that the cross-currents anchored by the screen test - between origin myths and cautionary tales, romance and realism, "Star-Land" and obscurity back home - would extend across the ocean itself. Preliminary research suggests that the screen test may have been imported to Europe from the US in the mid-to-late 'teens. For example, the French screen legend Musidora recalls meeting director Louis Feuillade for the first time in 1913, and his appraisal of her camera-worthiness does not seem to have included a screen test: "[Feuillade] was filming. After the lights went down, he approached me, held out his hand, and said kindly: 'Hello, Miss. Allow me to examine you. Walk. Turn. Come back this way. You're even prettier up close than from a distance" "(Cazals 1978: 28). Musidora then adds that she was hired on the spot, and began filming the next day (Cazals 1978: 28). By 1921, however, there is a reference in a popular film magazine to a "bout d'essai," or screen test, made by Sandra Milowanoff for Feuillade when he was making Les Deux Gamines the preceding year: "From the moment the first screen tests were hastily developed to see what Sandra Milowanoff would be like on screen, Louis Feuillade was transfixed" (Danvers 1921: 6). Musidora herself writes the same year about what to expect from a screen test, in an article addressed to "la débutante," or young woman trying to break into the business: "And there you are, doing a 'test' ('essai') 
for your first film. ... They lead you, like a condemned prisoner, to the gallows, in other words, to the film stage — or should we say the 'studio,' as the Americans do ... ." (“L’envers du cinéma” 1921: 6). Musidora's use of the second-person singular, in a direct address to the reader, breaks down the invisible "fourth wall" between speaker and audience; moreover, the actress's tone - alternately melodramatic and wry recalls the merging of romance and pragmatism that shaded accounts of the test in American magazines.

In the transnational, transformative process of star-making, then, the discourses surrounding the screen test became part of the cultural consciousness on both sides of the Atlantic - as did Prix de Beauté lead Louise Brooks. A star of silent pictures who did not make the transition to talkies, though she actually had a very good speaking voice; an actress who hailed from middle America (Kansas), but who endures in the cultural imagination as a leading lady of late 1920s European cinema, Brooks's intrinsic duality parallels that of the screen test itself. (Interestingly, in Selma Robinson's article "Could You Face the Camera?", the writer admits that though it often takes more than one screen test to determine potential, "[s]ome actresses like Louise Brooks are eminently successful the first time" [Robinson 1926: 107].) Hollywood itself found Brooks difficult to "place" - particularly at a historical period in which not only was the very voice of pictures changing, but so were notions of feminine allure. Brooks captured the style of the 1920s flapper, yet as Pabst would explore in Pandora's Box (1929), she also evoked the overtly destructive, vampiric sexuality of an earlier era. Laurence Reid of Motion Picture, reviewing Brooks's performance in A Social Celebrity (St. Clair, 1926), captured well the complexity of her appeal: "The provocative Louise Brooks . . . has screen personality. Her 
expressions have an impish playfulness. She has a manner of teasing you to join her, while at the same time she warns you to keep your distance" (Reid1926: 80).

By the end of the 1920s, however, Brooks had left Hollywood for a European film career. She starred in German films Pandora's Box and Diary of a Lost Girl (Pabst, 1929), before going on to make Prix in 1930. The break with Hollywood was acrimonious: after Brooks refused to do the voice recordings that would turn silent mystery The Canary Murder Case (St. Clair, 1929) into a talking picture, Paramount Pictures was, as she later recounted in her memoir, "so angry that they sent out a story, widely publicized and believed, that they had let me go because I was no good in talkies" (2000 [1982]: 104). Fan magazines duly circulated this story, connecting it to Brooks's exodus to Europe; consider Cal York's somewhat acerbic item in Photoplay's “Gossip of All the Studios” in November 1929: "When the microphone turned American pictures sour on her, Louise lit out for abroad . . . Plenty work, and no pestiferous mikes, and a little something in the envelope each and every week" (York 1929: 108).

In 1930, Cedric Balfrage of Motion Picture would take a more philosophical tone in "Their European Souls," citing Brooks as only one of a number of stars (including Anna May Wong and Virginia Bradford) who had left Hollywood following the rise of the talkies. Balfrage suggests that these performers "were really born European - though they didn't realize it at the time. In Hollywood they were, in a way, square pegs in round holes" (Balfrage 1930: 84). With its focus on the difficulties of literally finding a place in and/or out of Hollywood, this comment confirms that - as promised by the earliest accounts of screen tests and star-making overcoming the caprices of the movie camera ("It has strong likes and dislikes") did not guarantee surviving the vagaries of the industry itself. Indeed, the focus on 
Brooks's national identity parallels the discourse surrounding the transition to sound itself, in which, as Crafton notes, "there was a brief mini-crisis about the status of international speakers" and an accompanying debate over accented speech (Crafton 1999: 460). Yet Brooks's ambiguous appeal serves to illuminate all the more the transitional period of cinema in which she found herself, as well as the broader, porous topography of stardom - extending between a transcontinental Star-Land and obscurity. With this in mind, Brooks's performance as Lucienne suggests that Prix de Beauté belongs not to a single national cinema but, like that fateful diegetic screen test itself, a broader cross-cultural narrativization of star-making.

\section{What Price Beauty?}

The narrative of Prix mirrors the identification process between ordinary members of the public and film stars that was cultivated in fan magazines. Beginning the film as a typist for a newspaper (fittingly titled Le Globe), Lucienne enters a beauty contest without her fiancé's knowledge, and is chosen to become first "Miss France," and then "Miss Europe," which leads to the offer of a movie contract by a Prince Grabovsky (whose name parodically suggests a grasping film mogul). Simply, the film reinforces the fantasy that a typist could become a celebrity showered with expensive clothes and jewels who could be signed to a film production company by a prince. In Prix, the prince charming does not offer a castle, but rather a picture palace. The event that propels Lucienne to international fame is a beauty contest $-\mathrm{a}$ forum for discovery that, at first, seems fairly conventional. Spectators in both the United States and Europe would have recognized the beauty contest as a classic means of star-making; as Agnes Smith of Picture Play witheringly remarked in 1923, 
In the smaller communities, beauty contests are popular. Many motionpicture companies will agree to give the winner a chance to play a screen part. It is all good publicity, and it makes the home folks and the friends of the temporarily lucky girl feel good. And then what happens? With a brass band to see her to the depot, the girl and her parents depart for the Golden West, all ready for fame and fortune. The girl is introduced to the director who is usually polite about it. He gives her a screen test. (Smith 1923: 16)

Adding that "[t]here are plenty of tragedies around Hollywood" wrought by such hubris, Smith creates a bleak picture of the future for a provincial beauty queen. Yet in certain respects, film-star search competitions themselves resembled beauty contests, as an account from a 1915 edition of the British film magazine Pictures and the Picturegoer suggests. The article, entitled "A Gold-Medal Player: How Dorothy Rowan came to Act in Pictures", claims that "Miss Rowan is one of the very few young ladies who have secured, at first trial and without previous experience, a position on the stock company of a leading producing firm" (“A Gold-Medal Player," 91). Rowan describes her experience of participating in the Glasgow Cinematograph Competition of 1914:

... I had to act the test scene quite a number of times-first in the open competition, then in the semi-finals, and ultimately in the final. And I can tell you that the surprise of my friends was nothing to what I experienced 
myself when I heard my name announced as the winner of the gold medal. (“A Gold-Medal Player," 91)

With its whittling down of the number of competitors in successive rounds, the process described by Rowan serves as a precursor to the search for the next big film star both in the narrative of Prix and historically. Yet the beauty contest in Prix implicitly engaged with factors beyond its diegetic world. The transnationalism of the "Miss Europe" competition, for example, evokes the international mobility of movie stars before the advent of sound ended the Hollywood careers of many silent film actors whose English was deemed excessively accented. Also, the "Miss" in the titles "Miss France" and "Miss Europe" reflects the US origins of the beauty contest, as well as hinting at Brooks's own American background (and, allegorically, at the already hegemonic influence of Hollywood on European film industries). Beauty contests in the 1930s were sites of contested national identity as well as sites of gendered visual pleasure, which overlapped with those afforded by cinema (see, e.g., Ezra 2000: 21-46). According to Holly Grout, "Prix de beauté presented the beauty contest as a dynamic site of cross-cultural commercial exchange. The selection of Brooks as the leading lady thus verified how issues of national identity could be mutually framed and contested through venues that united female performance and commercial spectacle" (Grout 2013: 62). Grout goes on to emphasize the liminal nature of Brooks's appeal: "As Miss Europe Brooks is French and American at the same time that she is neither French nor American. Brooks, like Miss Europe, is paradoxically local and global, real and imagined, consumer and consumed" (Grout 2013: 63).

Prix further re-visions the familiar trope of the beauty contest by introducing a 
new phenomenon ("pour la première fois") in its execution: it would be judged solely by the audience ("sans jury"), in anticipation of X Factor-style mass popularity contests. The celebrity and the fan are mutually constitutive: without one, the other would not exist. Although the contest in Prix is determined by the applause of a live audience, the repeated close-ups of a loudspeaker prominently displaying the brandname "Gaumont," the name of one of the biggest French-based multinational production companies, anticipate the technological means that would facilitate the judging of later popular competitions-yet another sense in which this film is situated at the crossroads between two eras.

The technical reproducibility (or "mechanical reproduction") only hinted at in the beauty contest scene features much more prominently in other parts of the film. For example, in the waterfront scene at the beginning, among the other attractions, there is a man with a movie camera and a sign saying "Faites-vous filmer. 8 Francs" ("Have yourself filmed, 8 Francs"). This brief glimpse of the possibility, for anyone who can stump up the eight Francs, of starring in a little film, foreshadows the path that Lucienne will take. Lucienne is a typist at a newspaper who eventually ends up on film, at the precise historical moment that the medium itself is transitioning from the silent to the sound era (a number of graphic matches link typewriter keys to piano keys). Prix was shot as a silent film in 1929-just at the cusp of what Dudley Andrew has called the "sonic boom" in France (1995: 88-113) — and then a soundtrack was added in 1930, with Brooks's voice dubbed by Hélène Regelly. Sound reproduction, in the form of the gramophone, features in two pivotal moments in the film: at the beginning, after Lucienne has been reprimanded by her then-boyfriend for attracting the attention of men on the beach by performing stretching exercises as a gramophone plays; and when she is living a life of domestic drudgery in her marital home, and 
puts on the same song as she is visited by the man who offers her a job as a "grande vedette [big star]" in "films sonores [talking pictures]." Prix de Beauté, in other words, is a film in which the three components of Friedrich Kittler's landmark study (1999) Gramophone, Film, Typewriter converge.

It is this technical reproducibility that allows Lucienne's image (and voice) to endure after the woman herself has expired. In Prix, Lucienne's ultimate stillness contrasts starkly with the continuous running of the test footage even after her death, anticipating, as Mulvey (2006) notes, the new-media processes of reanimation through which historical footage is now viewed. Where Doane reads the film's final scene as an allegory of cinema's ability to turn living people into immortal icons, Mulvey hails it as the epitome of the "contradictory materialization of life and death" (2006: 176). Through Lucienne's stasis in death, the scene both illustrates the powerful role of the still image (the publicity photo, the film poster, etc.) in the star system, and anticipates the new modes of spectatorship available to viewers in the electronic age, when it is possible to pause a film at will on a particular actor: "Halting the flow of film extracts star images easily from their narrative surroundings for the kind of extended contemplation that had only previously been possible with stills” (Mulvey 2006: 161.) Moreover, the mechanical action of the test footage's unreeling at the end of the film - overtly uncanny, unsettling, as it is projected behind Lucienne's lifeless form - seems to correspond to the film's larger depiction of modern life. There are multiple scenes of "busyness" verging on chaos throughout the work, often involving either complex machinery (printing presses and typewriters) or large crowds: consider the opening scene at the waterfront; the fairground scene in which Lucienne is jostled by the crowds; the scene in which a crowd gathers in the street to hear details of the beauty contest blaring from loudspeakers; the large 
audience at the beauty contest in San Sebastian; and the scenes in which Lucienne is trailed by paparazzi. Lucienne's existential transaction is conveyed to the viewer as intrinsic to the contemporary condition: she essentially trades involvement with one form of mechanical reproduction (typing and, by extension, the newspaper) for another (cinema).

Lucienne's trajectory is a particularly gendered one, by virtue of both her job as a typist and the classic narrative of the ingénue's "big break." Shelley Stamp notes that " $[\mathrm{m}]$ any young women were encouraged to parlay their love of movies into an on-screen career, a fad propelled no doubt by the new star industry that celebrated the rise of 'ordinary' young women to the ranks of the nation's most beloved personalities. ..." (2000: 38). This new star industry was concomitant with the construction of the movie fan herself as iconically feminine. Kathryn Fuller notes that the term "fan" itself was associated with male sports supporters before the advent of cinema, but that male movie fans disappeared from fan discourse between 1915 and 1917, as "[p]opular culture in the 1920s helped reinforce the image of movie fandom as feminine" (Fuller 1996: 116, 118).

Interestingly, this gendered discourse links Betty in "The Test" and Lucienne in Prix across national and media boundaries. Like Betty's dilemma, Lucienne's conflict involves a struggle between her status as a wife and her desire for stardom. In both "The Test" and Prix de Beauté, moreover, a screen test comes between a woman and her possessive husband, though interestingly Betty is not ultimately forced to choose between the two: everyone lives happily ever after in the short story, and Betty's husband is given a job in the publicity department of the film studio, presumably going on to entice a whole new generation to aspire to his wife's position. The director expresses his weariness at being approached by thousands of young women 
who "want to go into pictures," adding, "You begin to believe that every woman in the United States, between the ages of sixteen and sixty, honestly thinks in her heart that she could make Mary Pickford look like September at the seashore, if only she had the chance" (Kummer 1917: 35). It is this chance that a career in movies affords, the golden ticket to fame and fortune.

Yet by virtue of the fact that its climactic scene centers on a screen test, Prix de Beauté emphasizes the possibility for an ordinary person, a real person, to become extraordinary, someone whose image is endlessly reproduced by mechanical means to become an abstraction. As Doane puts it, "[At the end of the film], André [Lucienne's husband] finally submits to the logic of mechanical reproduction, to the cinematic dialectic which insists - despite all evidence to the contrary - that 'this image is for you-and you alone" " (Doane 1991: 77). André is jealous not only of the producer who grasps Lucienne's hand during the screening, but of the way in which cinema makes his wife's beauty available to the masses. In dying, Lucienne may disappear physically, but she lives on in the particular kind of afterlife that cinema makes possible. In this way, the character Lucienne's death, and her "rebirth" as icon, brings to mind the king's two bodies in the ancien régime: Lucienne is dead; long live Lucienne.

Like the very performers it captured, the screen test would itself encounter shifts in technology and popularity, and experience a cultural afterlife thanks to processes of contemporary remediation (following Bolter and Grusin's term [2000]). Most famously, Andy Warhol made several Screen Tests in the 1960s, filmed portraits offering a wry commentary on the genre that were influenced by the liminality of conventional screen tests (see Angell 2006: 14, and Murphy 2012: 124-25). Today, footage once relegated to screening rooms and studio vaults is circulated widely on 
DVDs and on the web. As part of what has been termed a larger "neo-screen test," in which classic stars "negotiate a remediated identity in computer, television, and mobile phone screens" (Salzberg 2014: 152), raw footage is made available for the pleasure of fans rather than the contemplation of casting directors; particularly striking and representative of this is the continued popularity of the Gone With the Wind (Fleming, 1939) screen tests (Salzberg 2014: 176). And though modern-day studios still use the screen test as a tool for auditioning performers, the hopefuls themselves may - in the tradition of "How to Make Your Own Screen Test" (1926) produce and submit their own audition material. The internet is awash not only with screen tests of famous actors, but also with opportunities for unknowns to upload videos of themselves onto sites (including Facebook) where, it is promised, industry professionals will assess their talents. As the tagline for one such forum, Screen Test Star USA, announces, "This is a place to be discovered!"2 And so stars are born while the screen test continues its journey between diegetic representation and historical execution, film stock and print accounts, early cinema and new media. 


\section{Works Cited}

“All Aboard for Star-Land.” Photoplay September 1916: 51-54, 171.

Angell, Callie. Andy Warhol Screen Tests: The Films of Andy Warhol Catalogue Raisonné, vol. I. New York: Abrams, 2006.

"A Gold-Medal Player: How Dorothy Rowan came to Act in Pictures," Pictures and the Picture-goer, 1915, p 91.

Andrew, Dudley. Mists of Regret: Culture and Sensibility in Classic French Film. Princeton: Princeton University Press, 1995.

Balfrage, Cedric. “Their European Souls.” Motion Picture February 1930: 84, 96.

Benjamin, Walter. "The Work of Art in the Age of Mechanical Reproduction," in Illuminations. Trans. Harry Zohn. New York: Schocken Books,1969 [1935]. 217-51.

Bennett, Helen Christine. "What is a Screen Test?” Picture Play. May 1922: 18-21, 99.

Bolter, Jay David and Richard Grusin. Remediation: Understanding New Media. Cambridge: MIT Press, 2000.

Brooks, Louise. Lulu in Hollywood [Expanded Edition]. Minneapolis: University of Minnesota Press, 2000 [1982].

Cazals, Patrick. Musidora: La dixième muse ([?]: Henri Veyrier, 1978), 26; our translation.

Cox, Tracy. "Consuming Distractions in Prix de Beauté [1930]." Camera Obscura 50, $17.2(2002): 40-67$.

Crafton, Donald. The Talkies: American Cinema's Transition to Sound 1926-1931. Berkeley: University of California Press, 1999. 
Danvers, Guillaume. "Nos Grandes Vedettes: Sandra Milowanoff." Cinémagazine no. 40, October 21, 1921: 6. Available electronically at http://www.cineressources.net/images/periodiques/o000/636.pdf. Accessed 5 June 2014.

DeCordova, Richard. Picture Personalities: The Emergence of the Star System in America. Champaign: University of Illinois Press, 2001.

Doane, Mary Ann. Femmes Fatales. New York: Routledge, 1991.

Eisenhauer, Robert. Aftermyths: Hysteria, Colloquialism, and Caricature in the Age of Doubt. New York: Peter Lang, 2007.

Ezra, Elizabeth. The Colonial Unconscious: Race and Culture in Interwar France Ithaca and London: Cornell University Press, 2000.

Fuller, Kathryn H. At the Picture Show: Small-town Audiences and the Creation of Movie Fan Culture. Washington and London: Smithsonian Institution Press, 1996.

Grout, Holly. "Between Venus and Mercury: The 1920s Beauty Contest in France and America." French Politics, Culture and Society 31.1 (April 2013): 47-68.

Gustafson, Irene. "Putting Things to the Test: Reconsidering Portrait of Jason." Camera Obscura 77, 26. 2 (2011): 1 -31.

"How to Get In!: Authoritative Advice on How to Become a Photoplayer, by Leading Players and Directors." Motion Picture September 1916: 99-106.

“How to Make Your Own Screen Test," Photoplay, December 1926: 86.

Kingsley, Grace. "Extra Girls Who Became Stars.” Photoplay. April 1917: 67-70 and 145-146.

Kittler, Friedrich. Gramophone, Film, Typewriter. Trans. Geoffery Winthrop-Young and Michael Wutz. Stanford: Stanford University Press, 1997. 
Kummer, Arnold. “The Test.” Photoplay, December 1917: 34-38, 104.

---. “Signing up Cynthia.” Photoplay January 1918: 45-48, 132.

"L'envers du cinema," [author not given], Ciné pour tous, July 15, 1921, 6; our translation.

Morin, Edgar. The Stars. Trans. Richard Howard. Minneapolis: University of Minnesota Press, 2005 [1957].

Mulvey, Laura. Death 24x a Second. London: Reaktion Books, 2006.

Murphy, J. J. The Black Hole of the Cinema: The Films of Andy Warhol. Berkeley: University of California Press, 2012.

Picture-Play, September 1915, 32.

Powdermaker, Hortense. Hollywood - The Dream Factory: An Anthropologist Looks at the Movie-Makers. London: Secker and Warburg, 1951.

Reid, Laurence. “The Picture Parade.” Motion Picture. July 1926: 61-63, 80.

Robinson, Selma. “Could You Face the Camera?” Motion Picture July 1926: 37-38, 107.

Rogers, Bogart. “4 Million Dollars and 4 Men’s Lives.” Photoplay April 1930: 30 -33, 118-120.

Ronell, Avital. Test Drive. Champaign: University of Illinois Press, 2007.

Salzberg, Ana. Beyond the Looking Glass: Narcissism and Female Stardom in Studio Era Hollywood. New York and Oxford: Berghahn Books, 2014.

Smith, Agnes. "Beauty and the Beasts." Picture Play February 1923: 16-17.

Stamp, Shelley. Movie-Struck Girls: Women and Motion Picture Culture after the Nickelodeon. Princeton: Princeton University Press, 2000. 
Studlar, Gaylyn. “The Perils of Pleasure? Fan Magazine Discourse as Women's

Commodified Culture in the 1920s." Silent Film, ed. Richard Abel. New

Brunswick: Rutgers University Press, 1999. 263 - 297.

York, Cal. “Gossip of all the Studios.” Photoplay November 1929: 46-49, 76, 78, 81, 104-109.

${ }^{1}$ See Picture-Play, September 1915, 32.

${ }^{2}<\mathrm{https} / / / \mathrm{www}$. facebook.com/screenteststarusa/info/?entry_point=page_nav_about_item\&tab =page_info $>$, accessed 7 July, 2016. 